\title{
INTERACTIVE POTENTIAL OF NEWS NARRATIVES IN COMMUNITIES FORMED AROUND NEWS MEDIA
}

\author{
Artem Zakharchenko \\ Taras Shevchenko National University of Kyiv, 17a, Biloruska Street, \#16, Kyiv 04119, Ukraine
}

\begin{abstract}
The paper describes how the narrative features of highly shared news publications allow predicting the strength of their influence on social media communities. The Interactive potential was used as an indicator for measuring the strength of influence of news, which were classified on four levels of inner and external narrative structure. News stories published by popular Ukrainian media were taken as examples to show that the share of publications with inner narrative is low among high-influential articles, and the same holds for the share of publications that are parts of long or short media stories. In contrast, the articles, which could be embedded into the national narrative, and publications with certain issues of media agenda more often have high influence.
\end{abstract}

\section{KEYWORDS}

Media Influence, Interactive Potential, News Narrative, Social Action, Agenda-Setting

\section{INTRODUCTION}

Measurement of the influence of media publications on different groups and communities in social media is a complex issue, widely discussed in social (Bagozzi and Lee, 2002) and communication research papers (Gerbaudo, 2016), as well as in the information science investigations (Even-Dar and Shapira, 2011). Even more complicated is the issue of revealing the drivers of influence. Most of the papers that measure influence quantitatively do not go into mechanisms of influence. And vice versa, communicative researchers that analyze content do not use measurements or apply a simple parameter: the total number of article shares.

Researchers tried to reveal the interconnection between the number of shares and characteristics of shared content. In part, it is determined, that fake news usually is shared better than truthful because of their higher perceived novelty (Vosoughi et al., 2018). Negative news usually spread better than positive (Yan and Jiang, 2018). But in some situations reverse is true (You and Ju, 2018). (Nikolinakou and King, 2018) summarize that mobilizing emotions, both negative and positive, usually prompt sharing better than demobilizing ones. (Zengin Alp and Gündüz Öğüdücü, 2018) propose a mathematical model of different topics sharing.

But the number of shares is not the only indicator of influence. Interactive potential (IP) introduced in (Zakharchenko, 2017a) shows how strong was the influence of a media publication on the users of some social network community. This indicator shows how many interactions of news with users (in this research - 'likes', shares, or comments on Facebook) are, on average, caused by one previous interaction. If this value is $>1$, spreading is accelerated as a power function, but if $<1$, it gradually fades out. In a case of some particular number of interactions, for example, 10000 , IP shows whether this number is due to the strong influence of this publication on 10000 readers or weak influence on 1000000 readers. It is calculated as a slope factor (on logarithmic scale) of the line of dependence of publication interactions number on the so-called 'audience time' (substitute of the time, the number of page views of a sample of Ukrainian media) in the specific period of sharing (so called specific period, on which the network topology has no big influence).

This indicator was used in (Zakharchenko, 2019) to reveal how the strength of influence depends on the type of social action implied by sharing. Five types of sharing were detected. Four of them are Weber`s types of social actions: goal-rational, value-rational, affective, and traditional. The fifth, goal-rational (internalization), is singled out of the first-mentioned type, and means sharing just to inform followers, instead of other goal-rational shares aimed at actions outside the social networks. The media publications implying goal rational spreading have the highest IP, and therefore the strongest influence on the audience. Instead, the news intended for emotional actions, as a rule, are less influential, even if they have a high number of shares. 


\section{BODY OF PAPER}

Thus, our research question is such: is there any substantial interrelationship between the narrative features of news media publications and the strength of their influence on the news consumers' communities?

To answer this question the sample of the data used in (Zakharchenko, 2019) was taken and a narrative analysis of publications in it was provided. This dataset includes 827 publications of news website Ukrainska Pravda published from January 2016 to June 2017 and having at least 600 Facebook shares, likes, or comments. They dwelled on different topics: from politics and economics to sport and culture. The collected publications were divided into four ranges according to its IP value: 0-0.3; 0.3-1.0; 1.0-1.7 and over 1.7. Distribution of news according to the value of interactive potential corresponds to the normal distribution; the mode is 0.55 .

Ukrainska Pravda is one of the most visited Ukrainian news websites. It has a mild patriotic bias and one of the largest audience cores in Ukraine, so, there is a community of people who share its content.

The narrative analysis dealt with four narrative indicators detected in the news publications. Two trained coders detected four parameters applying different approaches of narrative analysis:

1. The first indicator is an inner narrative of publication. The categorical-form type of narrative analysis was applied. Here coders looked for stories in common, not strictly scientific sense. It is known that the persuasive ability of narrative is determined by the narrative structure (Busselle and Bilandzic, 2008, p. 266). Most of the typical news made by an 'inverted pyramid' scheme doesn 't have the narrative structure, as well as some long articles based only on facts and its analysis. In contrast, all publications applying the narrative style in all text or its parts like quotations were marked as publications with inner narrative as well as publications with clear 'Hollywood' structure (inciting incident, rising action, climax, resolution) or just publications that describe the temporal course of events, not just separate facts.

2. Belonging to 'short' or 'long' external narratives or appearance as a single publication. The holistic-content type of narrative analysis was applied. As determined in (Zakharchenko, 2017b), whole media narrative consists of plot lines with different lengths, and of separate single publications. In this paper the term 'long plot lines' was used for topics covered by the news media sample, which duration is more than 2 weeks without substantial decrease of coverage intensity and with more than 10 newsworthy events. Topics that had at least 2 newsworthy events and lasted up to 2 weeks were called 'short plot lines'. And other news publications were considered single. It was concluded that the weekly fluctuations in attendance of online-media were primarily due to fluctuations in the number of news stories of long plot lines. So, the audience usually follows long plotlines like a kind of TV series. In this paper, the same approach was used for coding.

3. Belonging to the national narrative. The holistic-content type of narrative analysis was applied. The national narrative as a comprehensive story about the origins of the nation, its development, justify the rules for its representatives and their relations with foreigners, is widely discussed (Khaldarova and Pantti, 2016; Krasodomski-Jones et al., 2019; Szostek, 2017). The feature of the Ukrainian nation is that it has no unified national narrative, instead, it has five different narratives (Korostelina, 2014). Taking into account the patriotic bias of Ukrainska Pravda, it was assumed that most of its readers agree with two patriotic narratives (according to Korostelina): 'Recognition of Ukrainian Ethnic Identity' and 'Fight for a Ukrainian ethnic identity'. So, in this section publications which could be embedded in one or both mentioned narratives were marked.

4. Agenda of publications. Social issues covered by media and called media agenda could be considered parts of the media narrative. The coding was based on the division of (Comparative Agendas Project, n.d.); its categories were amalgamated considering the Ukrainian realities. Seven categories were derived: Civil rights; Crime and corruption; Domestic commerce; Government operations and internal politics; Humanitarian (health, education, religion, culture); Social welfare and householding; War (foreign policy, defense).

Intercoder reliability was $87.3 \%$, disagreements were resolved by the author of the paper.

Distribution of all coded parameters showed a strong dependence on IP value. Specifically, the share of publications with an inner narrative decreased with the rise of the IP. (See Figure 1.) Publications with inner narrative usually induced emotional or goal-rational (internalization) shares which usually had low IP value. The sharing message could be formulated as 'Let's read this story'. Conversely, value-rational and goal-rational shares usually were caused by crude facts. 


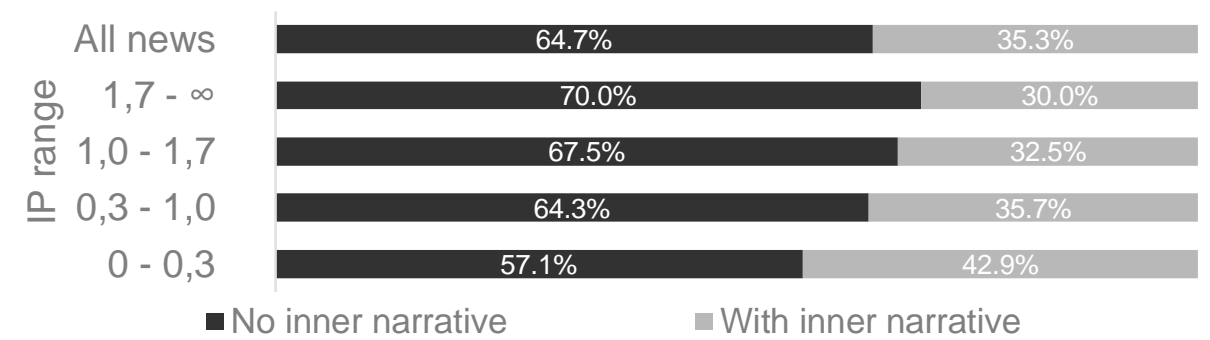

Figure 1. Share of publications with inner narrative and without it depended on the IP range

A similar pattern can be established regarding the external narratives and its length. (See Figure 2.) Publications that are parts of long and, especially, short stories rarely attained high IP values. High-intensity goal-rational and value-rational shares usually were caused by single stories. In contrast, short stories predominantly provoked emotional shares.

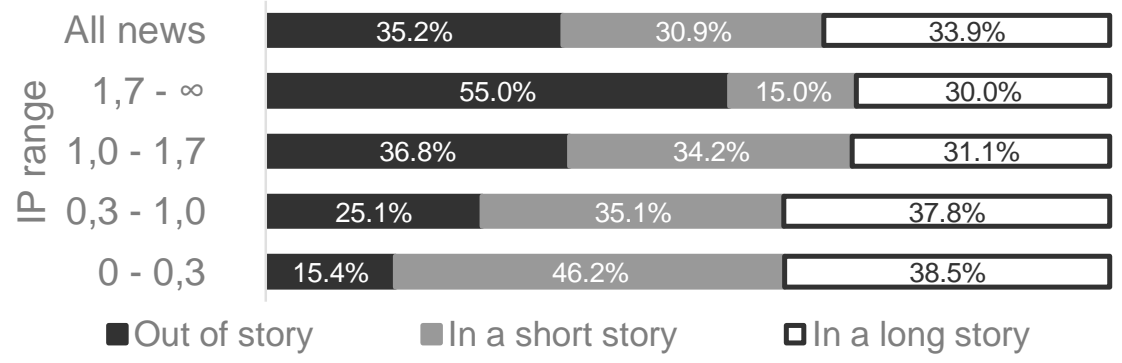

Figure 2. Share of publications embedded in short, long news narratives, and of single stories depended on the IP range

News embedding into the national narrative showed the opposite effect. (See Figure 3.) A higher share of publications that could be embedded into the national narrative is in the highest IP range. This is due to the value-rational type of news sharing with this narrative and, to a lesser extent, by goal-rational sharing; indeed, national narratives usually do not employ a simple emotional mood of sharing.

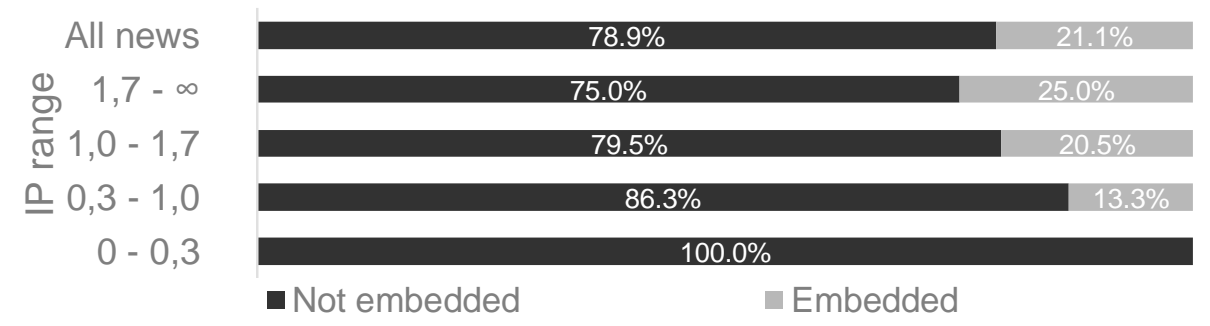

Figure 3. Share of publications embedded in the national narrative depended on the IP range

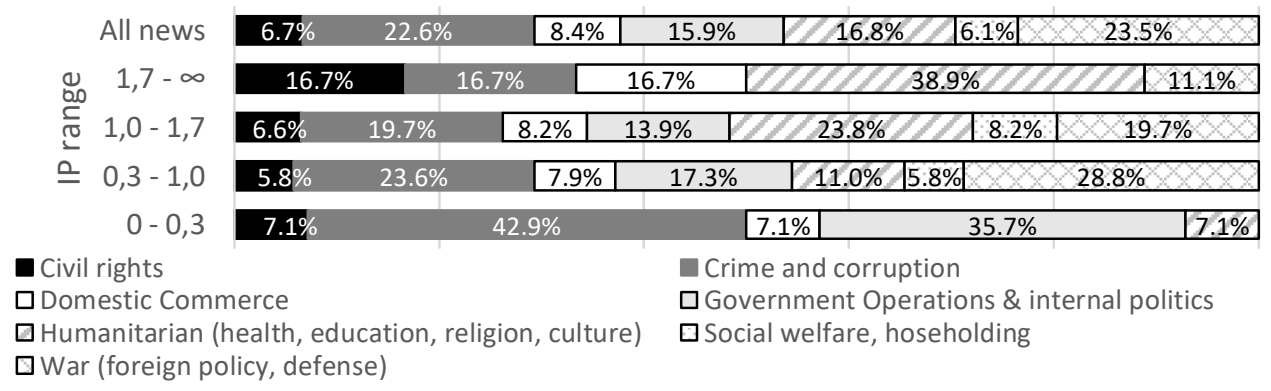

Figure 4. Share of publications with different agendas, depending on the IP range

The dependence of agenda on IP is a bit more complicated. (See Figure 4.) Some issues which share decreases with the growth of IP may be singled out. These are Crime and corruption, Government operations and internal politics, and War. They all were predominantly shared in an emotional mood, even stories about 
war that usually could be embedded into the national narrative. The share of other issues grew with the increase of IP, including Civil rights, Humanitarian (health, education, religion, culture) and Domestic commerce. This corresponds to the predominant type of shares: value-rational for the Civil rights and Humanitarian issues, and goal-rational (internalization) for Domestic commerce and Social welfare and householding issues.

\section{CONCLUSION}

The research shows that the Interactive potential and correspondingly the strength of influence depends on the narrative features of shared news content. Some narrative indicators are more common for news with high IP, while others for low. In each case it can be attributed to the type of sharing as social action which is predominant for this indicator value. So, there is a three-level dependence. The narrative features with other content parameters like sentiment, topic, lexicon, etc. determine the type of sharing and the strength of influence. Meanwhile, these two parameters are not completely independent: the type of sharing usually corresponds with particular IP diapason, as it is shown in (Zakharchenko, 2019).

No doubt, the mechanism of this determination could be different in different audiences. Though the question requires further study with different datasets, even now the findings of this paper may be used to create messages with a higher influence on particular parts of the media audience.

\section{REFERENCES}

Bagozzi, R.P., Lee, K.-H., 2002. Multiple Routes for Social Influence: The Role of Compliance, Internalization, and Social Identity. Social Psychology Quarterly. Vol. 65, Is. 3, pp. 226.

Busselle, R., Bilandzic, H., 2008. Fictionality and perceived realism in experiencing stories: A model of narrative comprehension and engagement. Communication Theory, Vol. 18, Is. 2, pp. 255-280.

Comparative Agendas Project, n.d. CAP Topics [WWW Document]. URL https://www.comparativeagendas.net/pages/master-codebook

Even-Dar, E., Shapira, A., 2011. A note on maximizing the spread of influence in social networks. Information Processing Letters, Vol. 111, Is. 4, pp. 184-187.

Gerbaudo, P., 2016. Rousing the Facebook Crowd: Digital Enthusiasm and Emotional Contagion in the 2011 Protests in Egypt and Spain. International Journal of Communication. Vol. 10, pp. 254-273.

Khaldarova, I., Pantti, M., 2016. Fake news. The narrative battle over the Ukrainian conflict. Journalism Practice. Vol. 10, Is. 7, pp. 891-901.

Korostelina, K.V., 2014. Constructing the narratives of identity and power: Self-imagination in a young Ukrainian nation. Lexington Books, Lanham.

Krasodomski-Jones, A. et al, 2019. Warring Songs: Information Operations in the Digital Age. London: Demos.

Nikolinakou, A., King, K.W., 2018. Viral video ads: Emotional triggers and social media virality. Psychology and Marketing. Vol. 35, pp. 715-726.

Szostek, J., 2017. The Power and Limits of Russia's Strategic Narrative in Ukraine: The Role of Linkage. Perspectives on Politics. Vol. 15, Is. 2, pp. 379-395.

Vosoughi, S. et al, 2018. The spread of true and false news online. Science. Vol. 359, pp. 1146-1151.

Yan, X., Jiang, P., 2018. Effect of the dynamics of human behavior on the competitive spreading of information. Computers in Human Behavior. Vol. 89, pp. 1-7.

You, M., Ju, Y., 2018. Preferring negative or positive news? A closer examination of journalistic negativity in a health crisis. Atlantic Journal of Communication. Vol. 26, Is. 5, pp. 318-329.

Zakharchenko, A., 2019. Social Actions of Social Networks Users Triggered By Media Posts Content. Social Welfare: Interdisciplinary Approach, Vol. 2, Is. 8, pp. 53-65.

Zakharchenko, A., 2017a. Evaluating the social influence of internet media news. Civitas et Lex, Vol. 3 (15), pp. 7-21.

Zakharchenko, A., 2017b. Serial structure of the online media narrative. Studia Methodologica, Is. 45, pp. 103-112.

Zengin Alp, Z., Gündüz Öğ̈̈dücü, Ş., 2018. Identifying topical influencers on twitter based on user behavior and network topology. Knowledge-Based Systems. Vol. 141, pp. 211-221. 